\title{
OUVIDORIA ITINERANTE: PROJETO “A AGIR QUER OUVIR VOCÊ!!”
}

\author{
Vitor Zanella Junior ${ }^{1}$ \\ Vanessa Fernanda Schmitt ${ }^{2}$ \\ Ana Claudia Hafemann ${ }^{3}$
}

\begin{abstract}
Resumo
O presente artigo científico discorrerá acerca das Ouvidorias Públicas no setor do saneamento básico, relatando a experiência do projeto de Ouvidoria Itinerante "A AGIR quer ouvir você!", desenvolvido pelo setor de Ouvidoria da AGIR - Agência Intermunicipal de Regulação do Médio Vale do Itajaí. O objetivo principal do projeto é estreitar os laços com os cidadãos, indo ao encontro deles nas ruas e praças de cada município regulado, oportunizando espaço para registro de demandas relacionadas aos serviços de saneamento, pedidos de esclarecimentos, participação em pesquisa de satisfação, entre outras interações. Nesse sentido, serão detalhadas todas as rotinas de trabalho desenvolvidas pela equipe responsável pela execução do projeto, bem como os métodos e materiais utilizados para divulgação e realização de visitas a cada município atendido. Ao final, serão demonstrados os resultados obtidos com a realização dessa prática, destacando, dentre eles, o aumento significativo de manifestações registradas na Ouvidoria da AGIR.
\end{abstract}

Palavras-chave: Ouvidoria Itinerante. Participação Popular. Controle Social. Saneamento Básico.

1 Bacharel em Direito; Especialista em Gestão e Políticas Públicas Municipais; Pós-Graduando em Gestão Ambiental em Municípios; Ouvidor da AGIR - Agência Intermunicipal de Regulação do Médio Vale do Itajaí. (ouvidoria@agir. sc.gov.br) (www.agir.sc.gov.br) Tel. (47) 3331-5827

2 Bacharel em Secretariado Executivo; Bacharel em Administração; Tecnóloga em Processos Gerenciais; Especialista em Auditoria em Sistemas e Serviços de Saúde; em Gerência de Cidades; em Controladoria da Gestão Pública Municipal; em Educação a Distância: Gestão e Tutoria; Mestre e Doutoranda em Desenvolvimento Regional. (vanessa@agir.sc.gov.br)

3 Administradora; Especialização em Gestão e Políticas Públicas Municipais; Pós-Graduanda em Educação a Distância: Gestão e Tutoria; Mestranda em Desenvolvimento Regional. Atualmente é Agente Administrativa na Agência Intermunicipal de Regulação do Médio Vale do Itajaí - AGIR. (ana@agir.sc.gov.br) 


\begin{abstract}
This scientific article is about the Public Ombudsman regarding the basic sanitation sector, telling the Itinerant Ombudsman project experience "A AGIR quer ouvir você!" developed by the ombudsman department of AGIR - Agência Intermunicipal de Regulação do Médio Vale do Itajaí. The project's main objective is to strengthen the relationship with the citizens, meeting them on the streets and public squares of every associated city, giving the chance to space for register of demands related to sanitation services, clarifying requests, participation in satisfaction surveys, and other interactions. Therefore, work routines developed by the responsible project execution team will be detailed, as well as the methods and materials used to divulgation and realization of visits to each associated city. At the end, the obtained results will be shown, highlighting, between them, the significant gain of registered demands at AGIR's Ombudsman.
\end{abstract}

Keywords: Itinerant Ombudsman. Popular Participation. Social Control. Basic Sanitation. 


\section{INTRODUÇÃO}

Visando estimular a participação ativa da população na gestão dos serviços públicos de saneamento básico e ao mesmo tempo fazer a divulgação institucional da Agência Reguladora, em especial do canal de Ouvidoria, surgiu o projeto "A AGIR quer ouvir você!", que percorre mês a mês as ruas e praças dos catorze municípios fiscalizados na região do Médio Vale do Itajaí em Santa Catarina, quais sejam: Apiúna, Ascurra, Benedito Novo, Blumenau, Botuverá, Brusque, Doutor Pedrinho, Gaspar, Guabiruba, Indaial, Pomerode, Rio dos Cedros, Rodeio e Timbó. O intuito dessas visitas é promover a resolução de demandas apresentadas pela comunidade local e inseri-la no contexto da regulação dos serviços de saneamento básico em seu município.

Assim, será abordado neste estudo o propósito de uma Ouvidoria com postura proativa contrapondo-se à tradicional postura eminentemente reativa das Ouvidorias Públicas, a qual depende da manifestação do cidadão para que sejam demandados os órgãos responsáveis para resolução das questões registradas (ABO; OMD, 2014).

Em contrapartida, atitudes proativas da Ouvidoria, como o referido projeto de Ouvidoria Itinerante, buscam inserção dos usuários dos serviços públicos de saneamento básico por meio da participação popular e controle social, indo ao encontro deles nas ruas e praças dos municípios para ouvir suas opiniões, conscientizá-los por meio de educação ambiental e registrar eventuais reclamações quanto a esses serviços prestados pelo Poder Público ou concessionárias de serviços públicos.

Outrossim, assevera ROMÃO (2011), ex-Ouvidor-Geral da União, que o atendimento realizado pelas Ouvidorias implica "alçar" o cidadão à condição de coautor das soluções e resultados produzidos no processo de participação popular. Da mesma maneira, BIAGINI e GOMES (2013, p. 13) entendem que "o instituto das Ouvidorias, quando consolidado, pode tornar-se um verdadeiro instrumento de controle social, atendendo às necessidades da sociedade e contribuindo poderosamente para o fortalecimento da democracia".

Foi então, em meados do mês de agosto de 2015, que o setor de Ouvidoria da Agência Reguladora deu início a essa prática, cujo objetivo é ofertar amplo acesso aos usuários dos serviços de saneamento básico à Ouvidoria, pois, mesmo considerando a existência dos canais tradicionais ofertados ao público, como site, correio eletrônico, telefone e atendimento presencial, faz-se necessário ir ao encontro do cidadão, nos municípios regulados, para aproximar o cidadão da Agência e também incentivá-lo ao exercício do controle social da prestação dos serviços de saneamento básico em seu município.

\section{OUVIDORIA ITINERANTE}

Cada visita da Ouvidoria Itinerante aos municípios regulados conta com a participação de uma equipe composta por três funcionários da Agência Reguladora, dentre eles um Ouvidor, um assessor de imprensa e um estagiário, que promovem a divulgação institucional por meio de panfletagem de fôlderes e informativos acerca da atuação da Agência no âmbito da regulação, controle e fiscalização dos serviços públicos municipais de saneamento básico. Também é realizada pesquisa de 
satisfação com a população, mediante questionário subdividido em três dos principais vetores do saneamento básico, quais sejam: abastecimento de água, esgotamento sanitário e manejo de resíduos sólidos. Além disso, dá-se oportunidade para que qualquer indivíduo apresente para a AGIR suas reclamações em relação às operadoras de saneamento e/ou ao Poder Público, sendo que, a partir desse momento, a Ouvidoria da Agência atua como intermediadora dos interesses do usuário perante os órgãos demandados.

Previamente a essas visitas, são realizadas divulgações de notas nos canais virtuais da Agência e em jornais e rádios locais para noticiar a ida desses profissionais ao município e incentivar a participação da população.

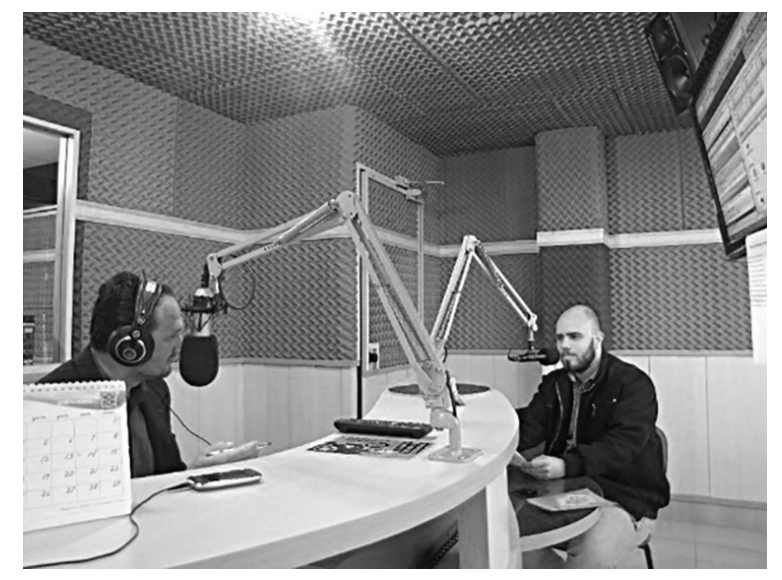

Entrevista na Rádio Nova FM (103.9), em Indaial/SC, no dia 11 de setembro de 2015.

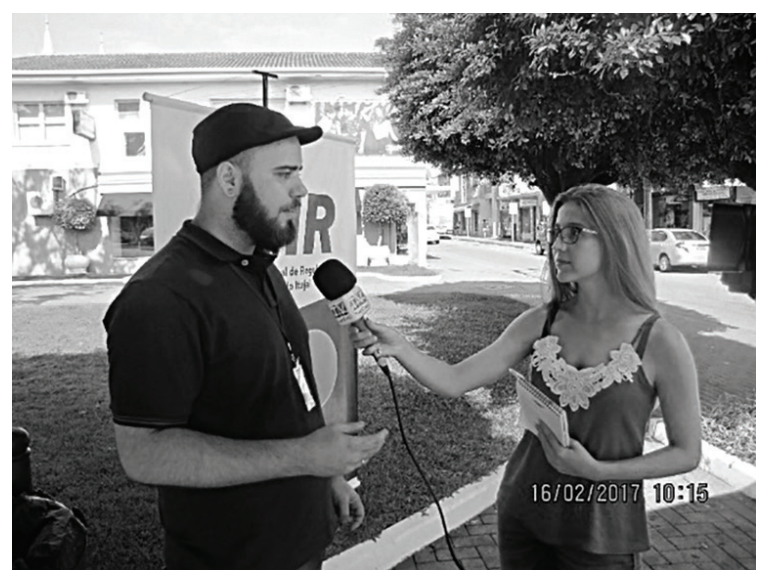

Entrevista para a TV Gaspar, em 16 de fevereiro de 2017, disponível em: http://www.tvgaspar.com.br/videos_detalhe. php?id_video=3020.

Além das ações de divulgação e abordagem da população, os agentes envolvidos neste projeto aproveitam as visitas aos municípios para realizar vistorias in loco nos SAC (Serviço de Atendimento 
ao Consumidor) e/ou Ouvidorias dos prestadores de serviços regulados e fiscalizados pela AGIR, para verificar as reais condições de atendimento aos usuários oferecidas pelas companhias, assim como disponibilizam os mesmos materiais informativos nesses locais de atendimento ao cidadão e afixam, em local de fácil visualização, adesivos com os contatos da Ouvidoria da AGIR para encaminhamento de manifestações, sejam elas pedidos de informações, reclamações, sugestões, denúncias e até elogios.

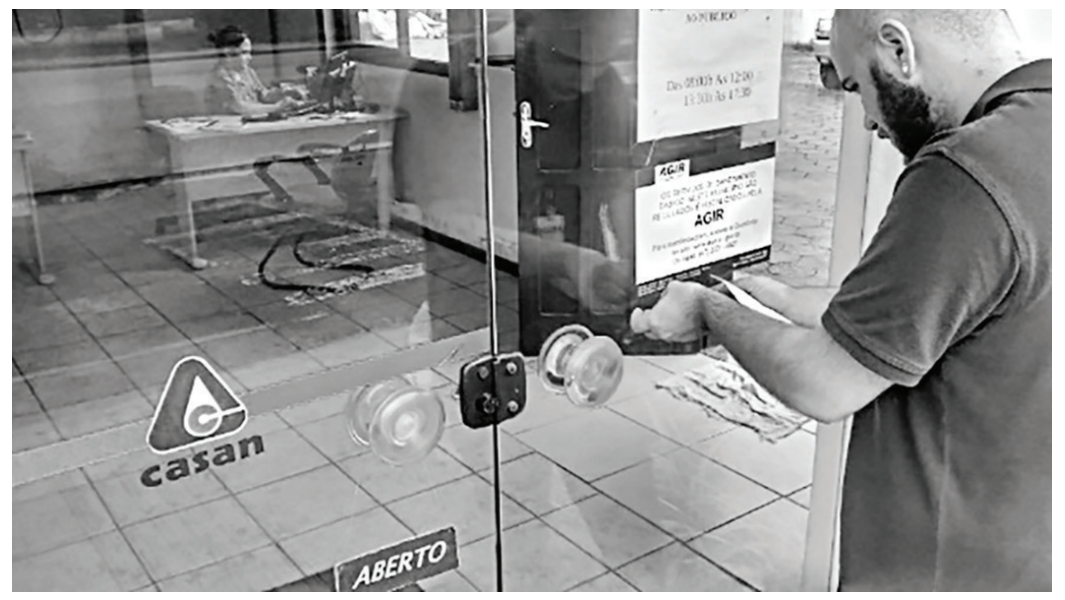

Adesivos da AGIR sendo colados na Agência da CASAN, em Guabiruba/SC, no dia 26 de novembro de 2015.

O conjunto dessas ações é que constitui o projeto "A AGIR quer ouvir você!", que percorre uma vez por mês cada um dos catorze municípios associados promovendo as ações acima descritas e pretendendo atingir o número máximo de usuários dos serviços de saneamento básico.

\section{PROJETO: “A AGIR QUER OUVIR VOCÊ!"}

O projeto "AAGIR quer ouvir você!" vai ao encontro do cidadão onde quer que ele esteja, assim, a Ouvidoria não aguarda apenas as demandas chegarem até a Agência, mas, pelo contrário, visa atingir o usuário que sequer tem noção de quais funções competem a um prestador de serviços de saneamento básico ou ao próprio Poder Público, bem como não sabe que pode contar com um canal de Ouvidoria para resolução de problemas no âmbito do saneamento básico. Nesse sentido, VOLPI, FORNAZARO e SAMPAIO (2011) asseveram que o Ouvidor é o legítimo representante dos interesses dos cidadãos, investido de autoridade para agir em sua defesa, bem como para conduzir a pretensão do cidadão perante as instâncias aptas ou competentes para apreciá-las.

As ações de uma Ouvidoria Itinerante têm a missão de atingir os usuários além daqueles que já sejam demandantes na Ouvidoria, isto para que, por meio das sugestões e reclamações da população, a Ouvidoria possa intervir positivamente para a solução de conflitos com as companhias de saneamento básico e/ou com o Poder Público. 


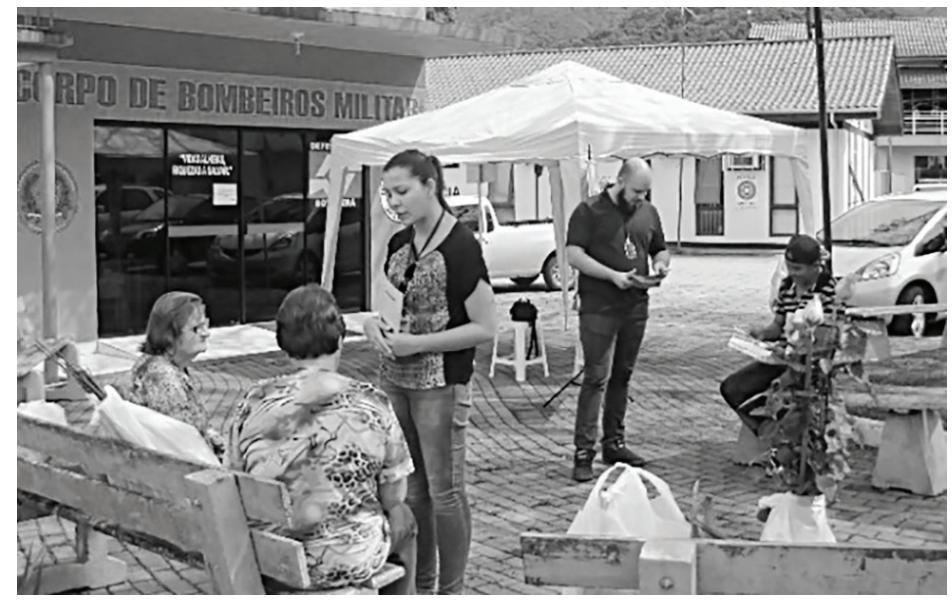

Equipe da AGIR abordando a população de Botuverá/SC, em 18 de outubro de 2016.

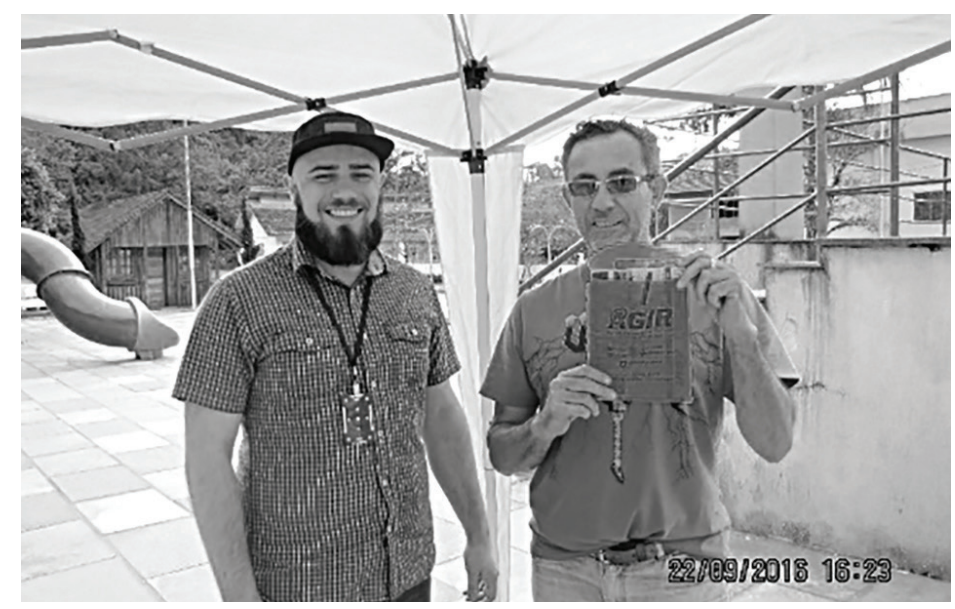

Ouvidor da AGIR junto ao usuário que recebeu material informativo da Agência em Benedito Novo/SC, no dia 22 de setembro de 2016.

Como reflexo das ações de uma Ouvidoria proativa, notamos que foi estimulado o senso crítico dos cidadãos, pois, a partir do momento que tomam ciência de seus direitos perante os prestadores de serviços de saneamento, passam a exigir que sejam cumpridos, via canal de Ouvidoria. Logo, CAMPOS e ALVES (2014, p. 11) afirmam que "são as Ouvidorias elementos de otimização da administração estatal; contudo, são também porta-vozes qualificados das demandas dos indivíduos, as quais devem ser atendidas a contento".

Doravante, convém demonstrarmos os resultados parciais da pesquisa de satisfação que está sendo realizada com a população dos catorze municípios visitados durante a segunda rodada de visitas do projeto, que ocorre com periodicidade mensal. Esta pesquisa é composta por sete questionamentos, o primeiro deles é se o cidadão entrevistado conhece a AGIR. Caso não conheça, a equipe presta breves esclarecimentos quanto à atuação e competências da Agência Reguladora, apresentando, também, o canal de Ouvidoria ao usuário para que encaminhe as demandas que 
tiver relacionadas a saneamento básico. Os demais questionamentos se referem à avaliação do usuário quanto à qualidade dos serviços de abastecimento de água, esgotamento sanitário, coleta de resíduos sólidos convencional, coleta seletiva, atendimento ao usuário realizado pelo prestador de serviços e também pela Agência Reguladora. Cabe salientar que cada questionamento referente aos serviços indicados é considerado no âmbito do município em que o entrevistado reside. Seguem abaixo os resultados parciais da pesquisa de satisfação:

\section{GRÁFICO 1 - Proporção em Porcentagem dos Municípios em que os Cidadãos Foram Entrevistados}

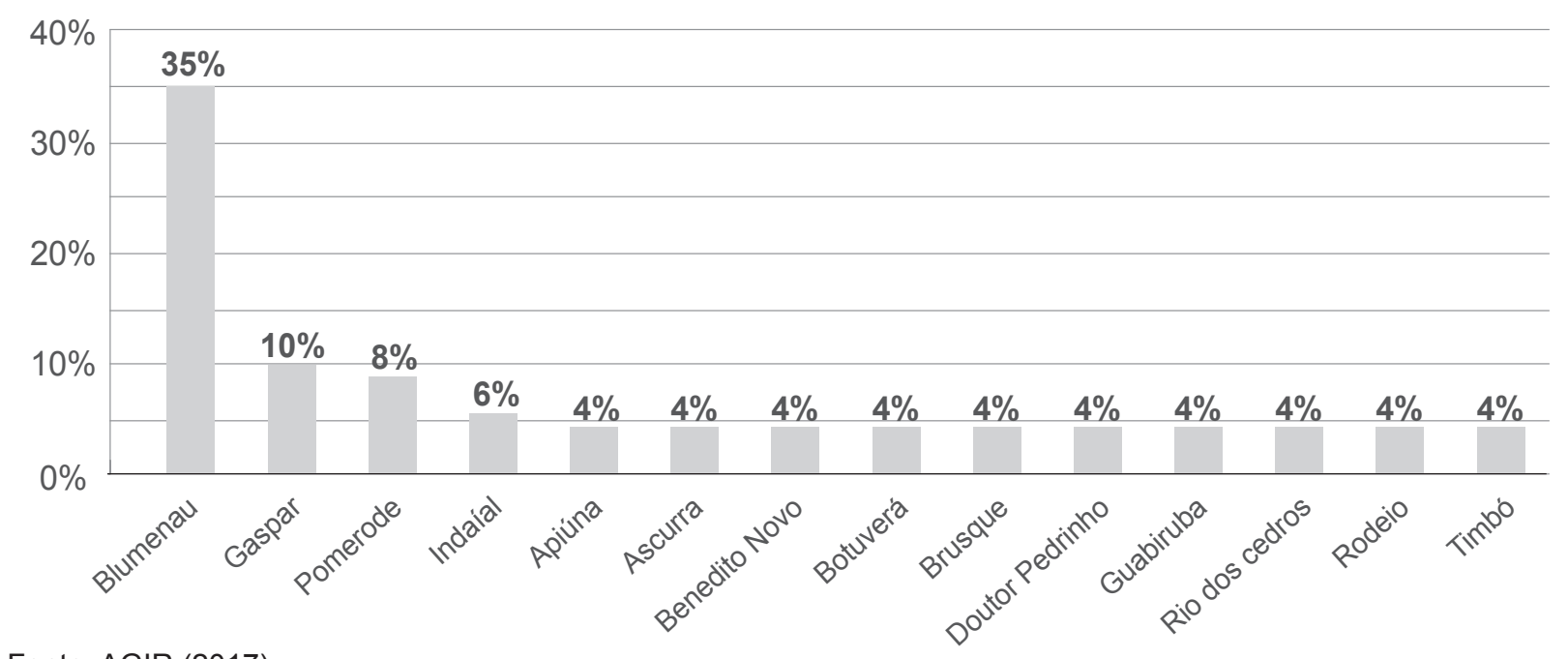

Fonte: AGIR (2017)

\section{GRÁFICO 2 - Resposta dos Cidadãos ao Questionamento: "Você conhece a AGIR?"}

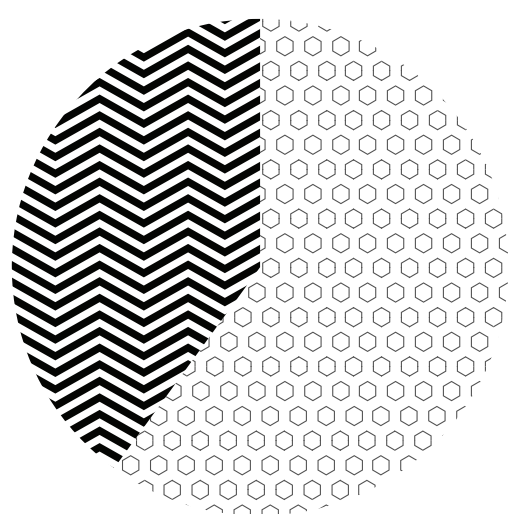

Fonte: AGIR (2017) 
Nos questionamentos seguintes, referentes à avaliação de qualidade dos serviços de água, esgoto e coleta de resíduos sólidos, eram apresentadas três diferentes respostas aos cidadãos: "Insatisfeito", "Satisfeito" ou "Muito Satisfeito", conforme o seu nível de satisfação referente a cada serviço prestado.

GRÁFICO 3 - Resposta dos Cidadãos ao Questionamento: "Como você avalia a qualidade do serviço de abastecimento de água?"

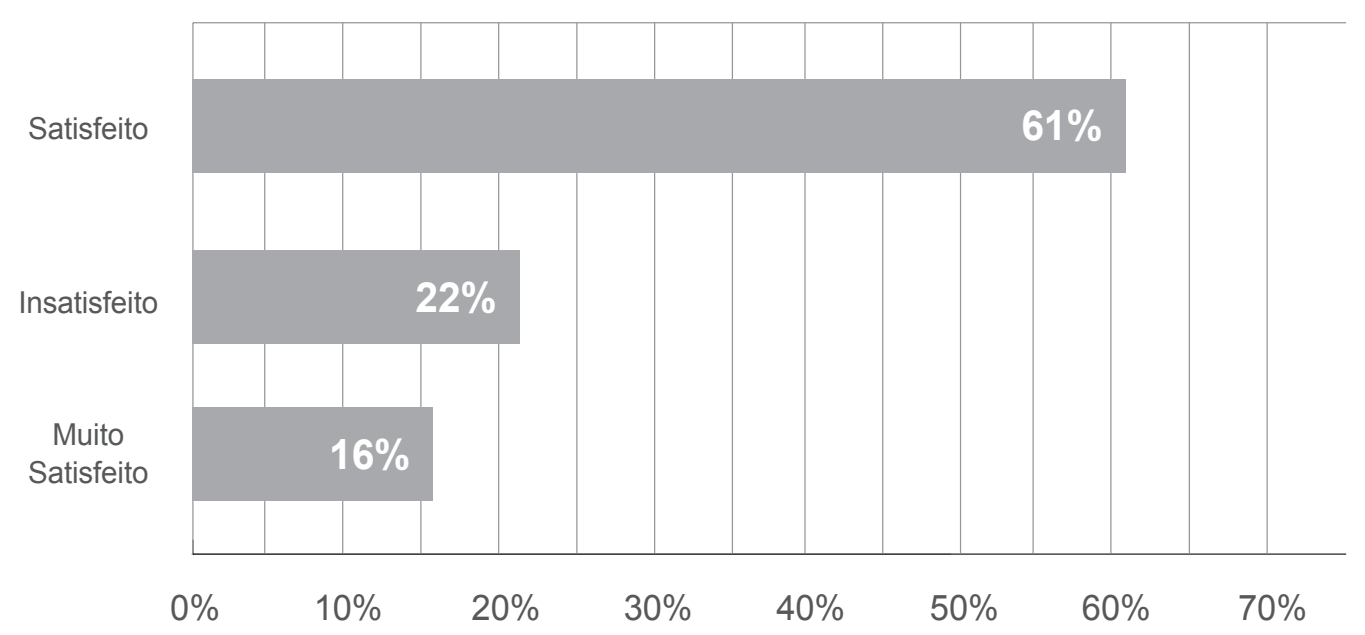

Fonte: AGIR (2017)

\section{GRÁFICO 4 - Resposta dos Cidadãos ao Questionamento: "Como você avalia a qualidade do serviço de esgotamento sanitário?"}

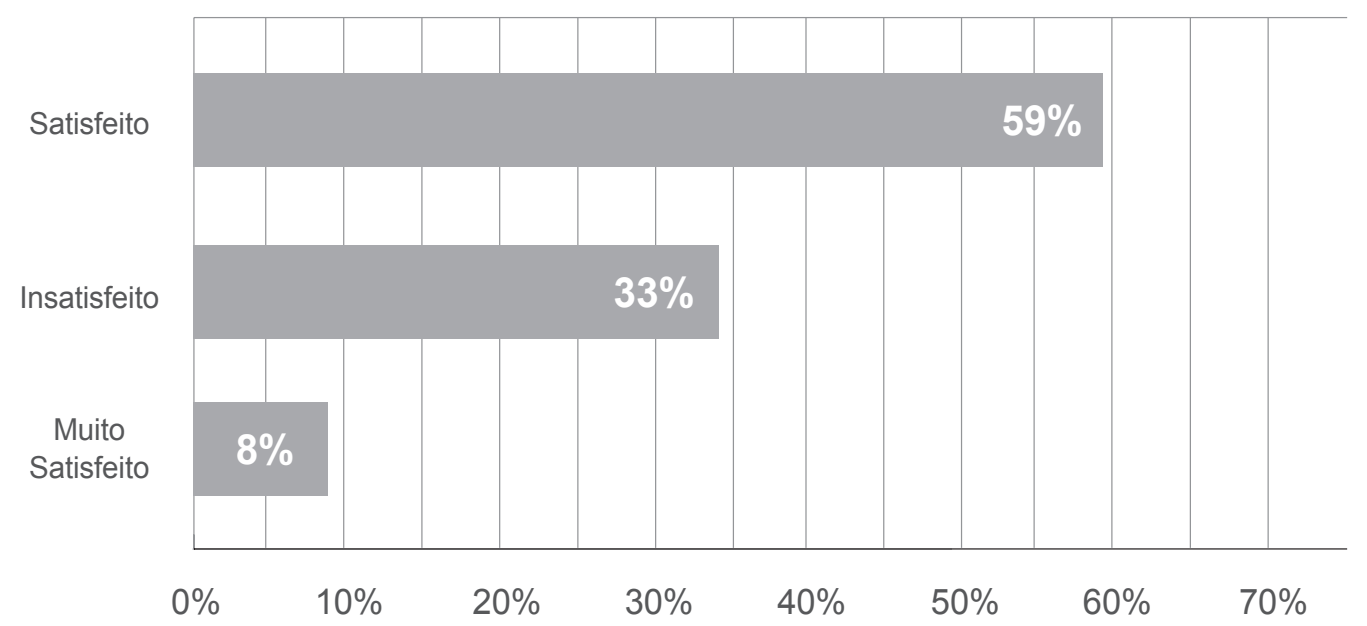

Fonte: AGIR (2017) 
GRÁFICO 5 - Resposta dos Cidadãos ao Questionamento:

"Como você avalia a qualidade do serviço de coleta dos resíduos sólidos?"

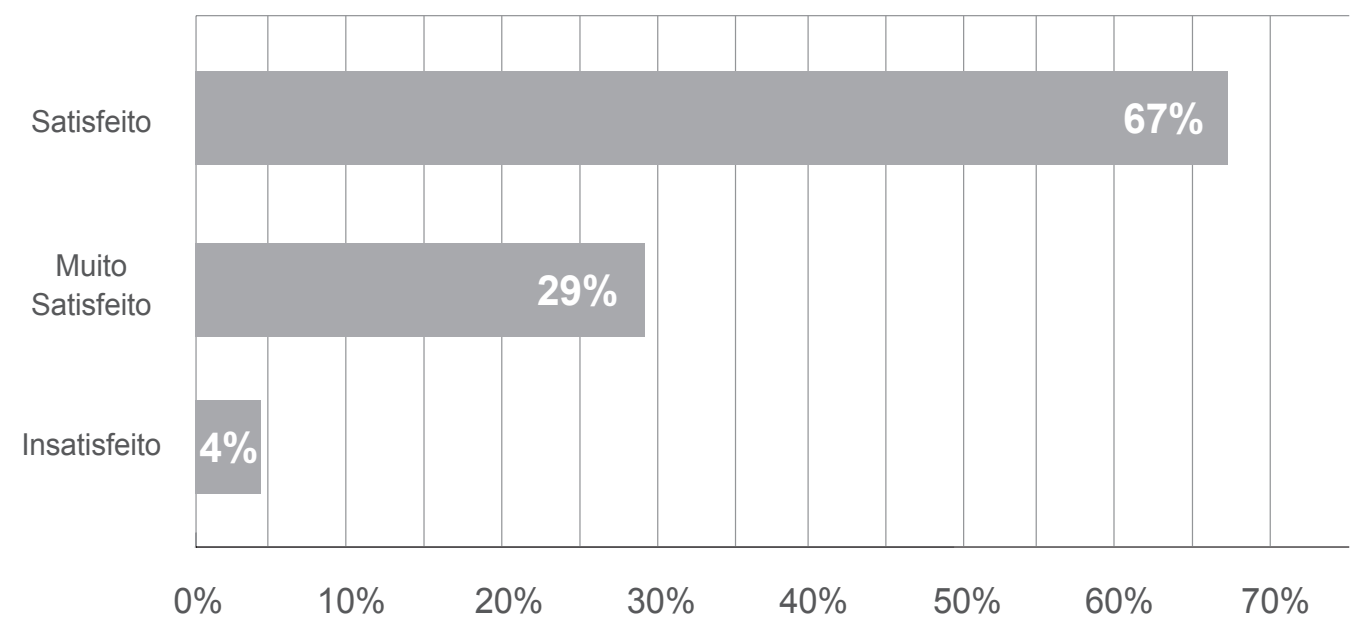

Fonte: AGIR (2017)

GRÁFICO 6 - Resposta dos Cidadãos ao Questionamento:

"Como você avalia a qualidade do serviço de coleta seletiva?"

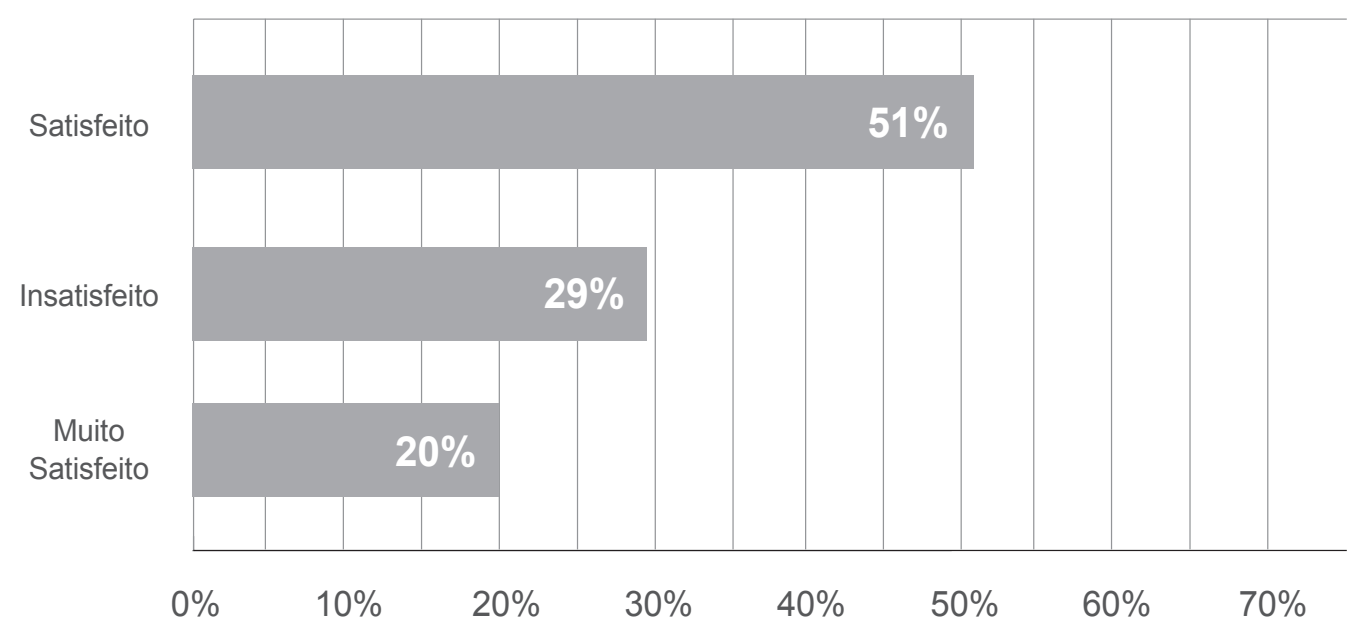

Fonte: AGIR (2017) 
GRÁFICO 7 - Resposta dos Cidadãos ao Questionamento:

"Como você avalia o atendimento ao usuário realizado pelo prestador de serviços de saneamento básico?"

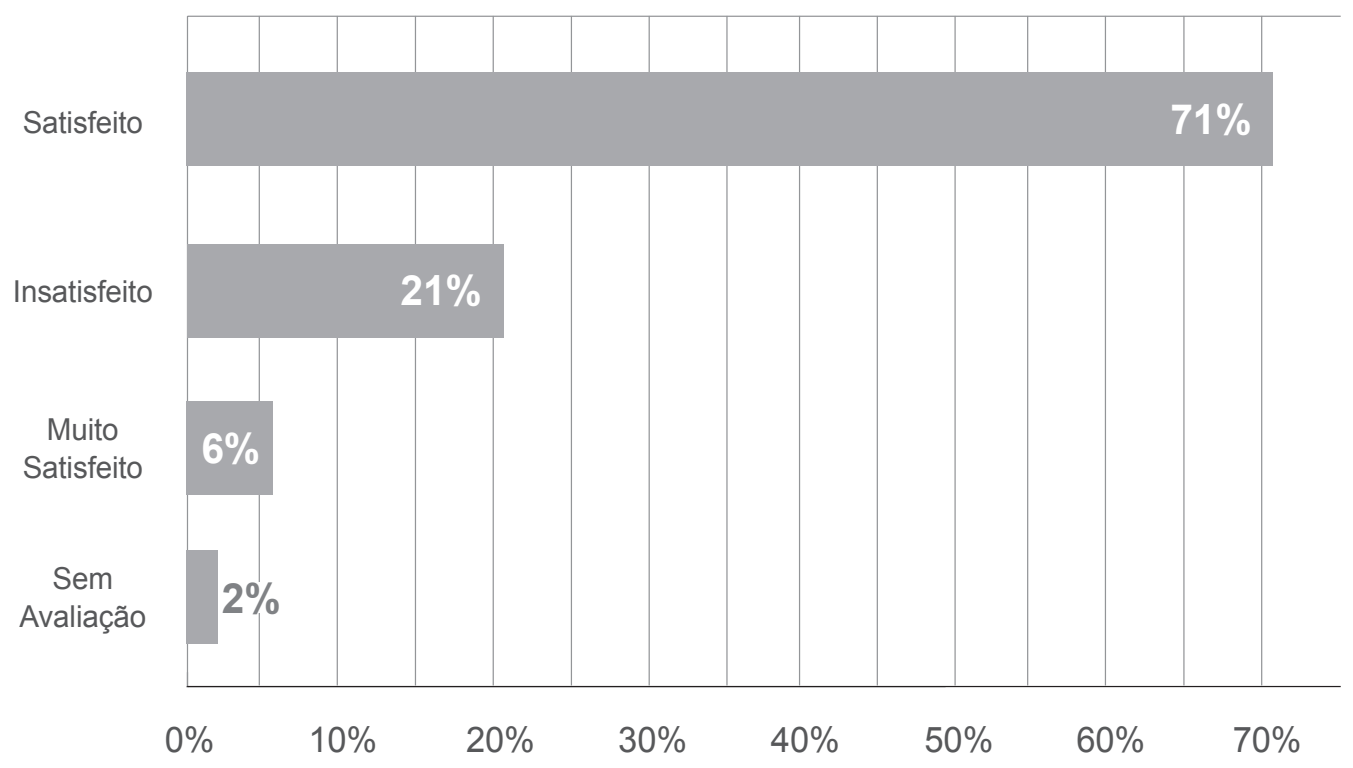

Fonte: AGIR (2017)

GRÁFICO 8 - Resposta dos Cidadãos ao Questionamento: "Como você avalia o atendimento ao usuário realizado pela AGIR?"

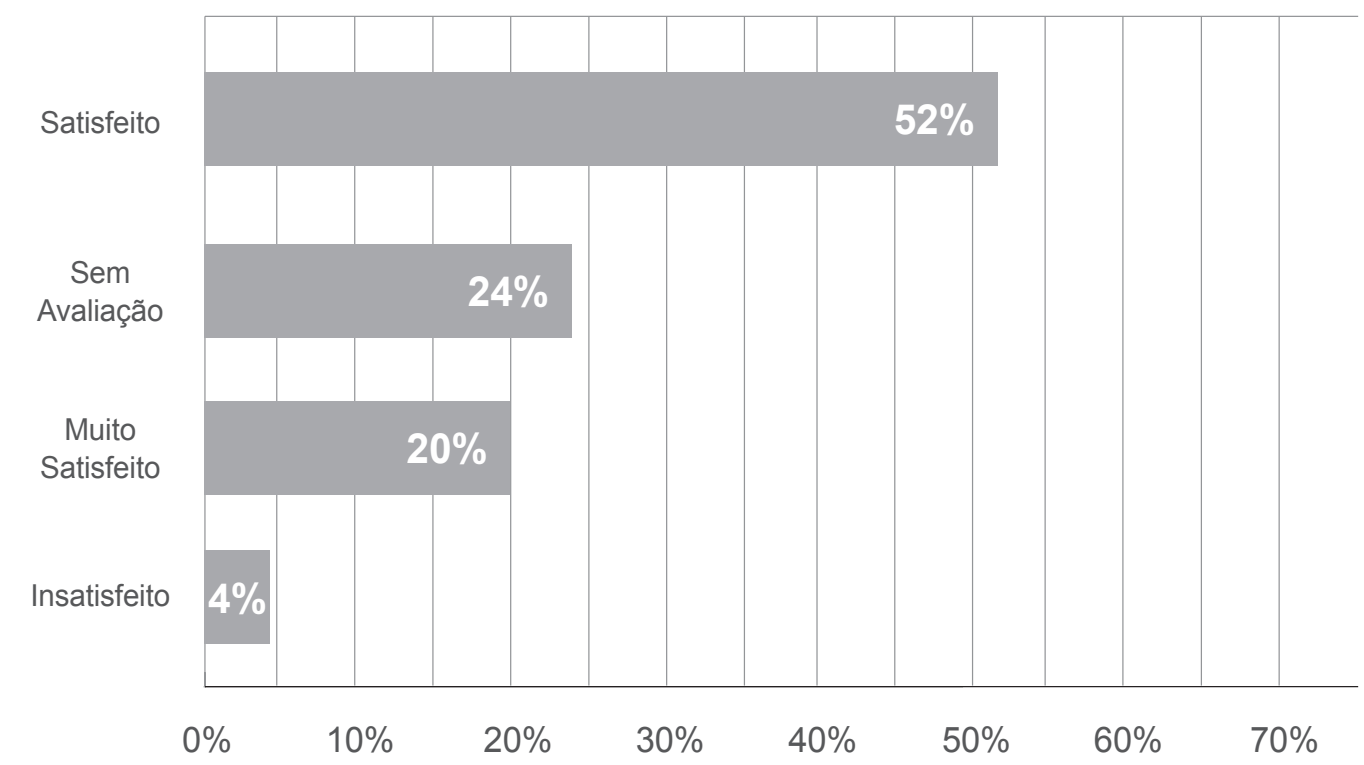

Fonte: AGIR (2017) 
Nos gráficos 7 e 8 (dois últimos), houve casos de ausência de avaliação por parte dos entrevistados em razão de eles nunca terem utilizado os serviços de atendimento ao usuário do prestador de serviços e/ou Agência Reguladora.

Ao final da pesquisa de satisfação é oportunizado espaço para registro de opinião, sugestão ou crítica quanto aos serviços de saneamento básico. Nesse sentido, podemos elencar que a maior parte das críticas da população relacionava-se com o atendimento do prestador de serviços realizado via call center e o atendimento prestado em regime de plantão. Seguidas a essas, também recebemos críticas em relação à descontinuidade do serviço de coleta seletiva no município de Blumenau/SC, bem como reclamações quanto ao alto valor pago a título de tarifa de esgoto no mesmo município.

Por outro lado, recebemos sugestões e propostas muito interessantes dos usuários, tais como: a criação de atendimento em regime de plantão também na Agência Reguladora, com suporte 24 horas, inclusive nos finais de semana e feriados. A população propôs também que fossem intensificadas as campanhas de educação ambiental, em especial quanto à necessidade de separação do resíduo reciclável, sugerindo que fossem promovidas palestras em escolas sobre o tema.

Igualmente, como resultado da promoção dessa prática, notou-se o aumento do número de manifestações registradas na Ouvidoria da AGIR, posto que o usuário passa a ver a Agência Reguladora como verdadeira aliada para a mediação com os prestadores de serviços. Dessa maneira, foi computado um aumento de $38 \%$ no número de demandas registradas entre o ano de 2015 , quando se iniciou o projeto de Ouvidoria, e o ano de 2016, mantendo-se o fluxo de atendimentos em patamar semelhante em 2017.

\section{GRÁFICO 9 - Quantidade de Demandas Registradas na Ouvidoria entre os Anos de 2015 e 2017}

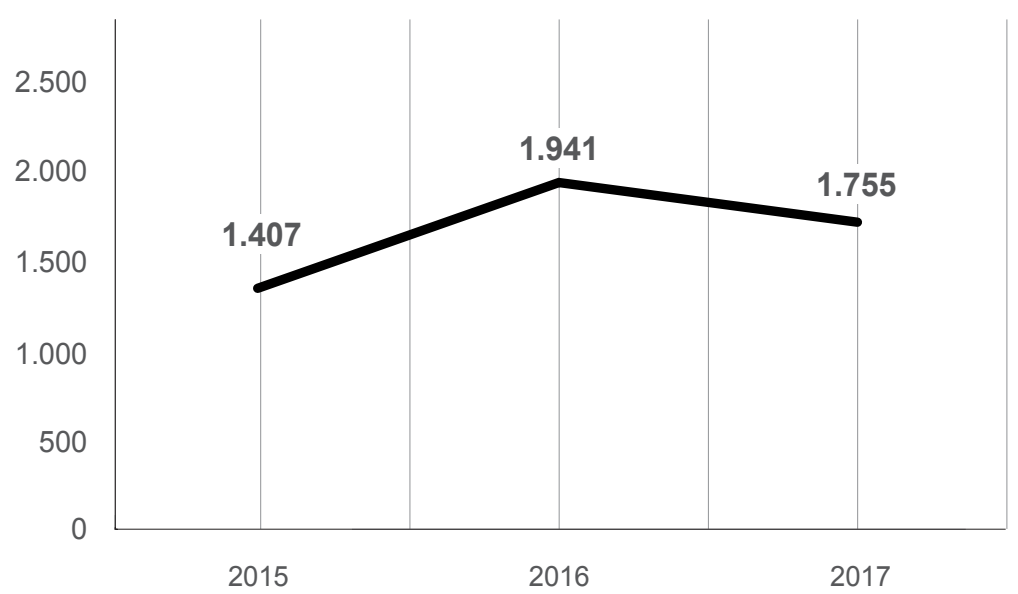

Fonte: AGIR (2017)

Destacamos que no gráfico acima foram consideradas as demandas registradas por meio telefônico, e-mails, sistema virtual de atendimento da Ouvidoria e atendimentos presenciais nesse pe- 
ríodo. Se considerarmos exclusivamente as demandas registradas durante as visitas da Ouvidoria Itinerante, temos: 7 em 2015, 17 em 2016 e 13 em 2017. À primeira vista, pode parecer que o número de atendimentos por meio do projeto não foi muito expressivo, contudo, temos de considerar que esse foi o primeiro contato realizado com muitos daqueles usuários, os quais passaram a conhecer sua Agência Reguladora, tornando-se potenciais futuros demandantes.

Ademais, como reconhecimento das ações desenvolvidas pelo projeto, em 16 de junho de 2016 a equipe da AGIR recebeu certificado de "Boa Prática" na premiação de boas práticas em gestão pública promovida pela Universidade do Estado de Santa Catarina - UDESC, em parceria com a Escola Superior de Administração e Gerências - ESAG.

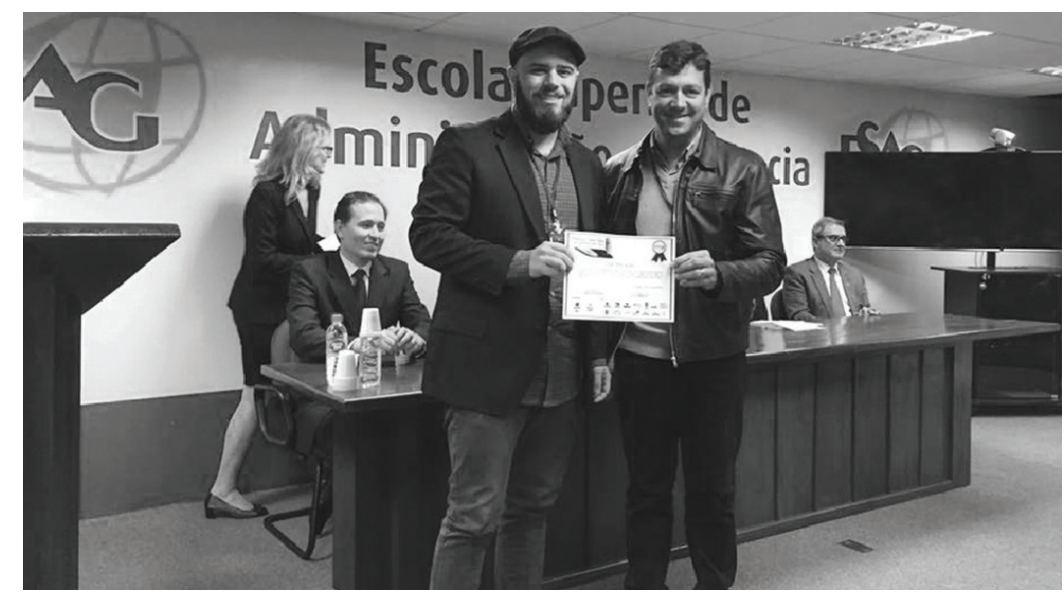

O Ouvidor, Vitor Zanella Junior, recebe em nome da AGIR o certificado de "Boa Prática" em Gestão Pública na premiação da UDESC/ESAG, em 16 de junho de 2016.

A referida premiação visou identificar, reconhecer, estimular e premiar práticas inovadoras de gestão, entendidas como um conjunto de ações e procedimentos que consolida avanços na realização do interesse público, implementado em órgãos públicos e em organizações da sociedade civil no Estado de Santa Catarina.

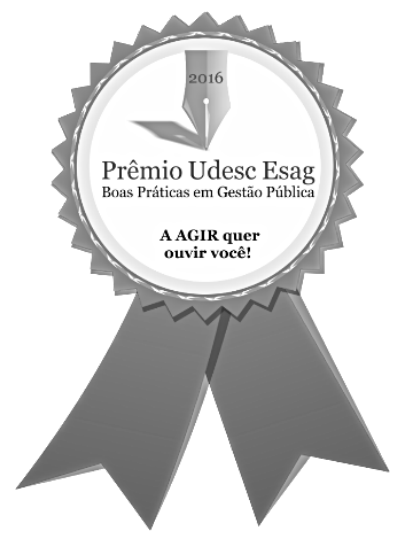

Selo recebido pela premiação de "Boas Práticas" em Gestão Pública da UDESC/ESAG 2016. 
Enfim, é importante destacar que são os usuários a parte principal na relação entre usuários, prestadores de serviços e poder público, e o projeto é voltado especialmente para eles, que necessitam de maior representatividade perante as companhias de saneamento básico e os órgãos públicos.

\section{CONSIDERAÇÕES FINAIS}

Em suma, este trabalho científico expôs uma prática exitosa idealizada pela AGIR com intuito de instigar a participação popular e o controle social dos usuários dos serviços de saneamento básico mediante uma Ouvidoria Itinerante, para garantir maior representatividade aos cidadãos que, por intermédio dela, podem participar ativamente da gestão dos serviços de saneamento básico com suas sugestões, reclamações, elogios, denúncias, entre outras manifestações.

O cidadão, como destinatário final dos serviços públicos de saneamento básico prestados pela Administração Pública, seja por meio da administração indireta ou até mesmo por concessionárias de saneamento, usufrui desses serviços essenciais sem muitas vezes ter garantido um direito de preferência, ou seja, habitualmente o Poder Público, e/ou seus permissionários, detém um monopólio natural sobre a atividade de saneamento básico desenvolvida, seja ela abastecimento de água, esgoto, limpeza urbana, coleta de resíduos sólidos ou drenagem de águas pluviais. Assim, é função da Ouvidoria da Agência Reguladora assegurar que sejam respeitados os direitos dos cidadãos nessa relação de consumo e proporcionar amplo acesso para encaminhamento de solicitações à Ouvidoria, seja via canais virtuais, telefone, pessoalmente ou por meio do projeto "AAGIR quer ouvir você!" em suas edições.

Por fim, o projeto "A AGIR quer ouvir você!" demonstrou-se uma prática relevante por permitir a inserção social no âmbito da regulação, controle e fiscalização dos serviços públicos de saneamento, por intermédio de um canal de Ouvidoria atuante, cuja responsabilidade é a de representar a vontade popular perante a Agência Reguladora e quaisquer órgãos ou empresas que sejam demandados em virtude dos serviços públicos prestados.

\section{REFERÊNCIAS}

ABO - ASSOCIAÇÃO BRASILEIRA DE OUVIDORES; OMD - SOLUÇÕES PARA OUVIDORIAS. Curso de atualização e certificação em Ouvidoria, 9-11 dez. 2014. Florianópolis-SC.

BIAGINI, Liane; GOMES, Marta Lopes. Ouvidoria: uma reflexão como instrumento de controle. Revista dos Mestrados Profissionais, v. 2, n. 1, jan./jun. ISSN: 2317-0115. 2013. Disponível em: < http://www.repositorios.ufpe.br/revistas/index.php/RMP/article/view/324>. Acesso em: 28 mar. 2018.

CAMPOS, Adriana; ALVES, Breno Barbosa Cerqueira. Ensaio sobre a contribuição das Ouvidorias Públicas para a Educação em Direitos Humanos e para a consolidação de uma cultura democrática no Brasil. Revista Jurídica (FIC), v. 01, 2014. Disponível em: <http://revista.unicuritiba.edu.br/index.php/RevJur/article/viewFile/789/602>. Acesso em: 27 mar. 2018

ROMÃO, José Eduardo Elias. O papel das Ouvidorias Públicas na efetivação do controle social. VII Fórum Brasileiro de Controle da Administração Pública: Direito Fundamental ao Bom Governo. Rio de Janeiro, 2011.

VOLPI, Edna Lúcia; FORNAZARO, Maria Inês; SAMPAIO, Maria Lumena Balaben. Mediação e Ouvidoria. In: PEREZ, José Roberto Rus; BARREIRO, Adriana Eugênia Alvim; PASSONE, Eric (Org.). Construindo a Ouvidoria no Brasil: avanços e perspectivas. Campinas: UNICAMP; 2011. p. 77-104. 